\title{
Formação docente dos cursos de licenciatura na UFBA: análise dos currículos
}

\author{
Educational training of the initial teacher courses at UFBA: curriculum \\ analysis
}

\section{Renata Meira Veras}

Professora doutora na Universidade Federal da Bahia, Salvador, Bahia, Brasil.

renatameiraveras@gmail.com - https://orcid.org/0000-0002-1681-1401

\section{Erika Silva Chaves}

Mestranda pelo Programa de Pós-Graduação Estudos Interdisciplinares sobre a Universidade, Universidade Federal da Bahia, Salvador, Bahia, Brasil.

erikachaves2003@yahoo.com.br - https://orcid.org/0000-0001-5196-270X

\section{Daiane da Luz Silva}

Mestranda pelo Programa de Pós-Graduação Estudos Interdisciplinares sobre a Universidade, Universidade Federal da Bahia, Salvador, Bahia, Brasil.

daiane@ufba.br - https://orcid.org/0000-0002-8177-5160

Recebido em 11 de maio de 2019

Aprovado em 07 de outubro de 2019

Publicado em 17 de dezembro de 2019

\section{RESUMO}

A formação de professores se constitui como um dos elementos decisivos para melhoria do sistema educacional, uma vez que a visão de profissionalismo docente subjaz a um determinado programa de formação, tanto no seu conteúdo, como na forma como está organizado. Com base nisso, esse estudo tem como objetivo analisar a carga horária das atividades formativas nos cursos de licenciatura da UFBA. A partir de uma pesquisa exploratória do tipo documental, foram analisadas 1.355 ementas de componentes curriculares obrigatórios distribuídos nos 38 currículos de cursos de licenciatura da UFBA, no turno diurno e noturno no período de abril/maio de 2018. Os resultados apontaram que com relação aos componentes que contemplam as dimensões pedagógicas, estágios supervisionados e práticas pedagógicas, cujos objetivos estão voltados para formação docente, os cursos que apresentaram expressiva carga horária foram o de Pedagogia, seguido de Teatro, Computação do turno noturno, Ciências Naturais e Educação Física. O curso que apresentou menor carga horária nesse grupo foi o de Dança do turno diurno. Sendo assim, verifica-se que a formação docente nos cursos de licenciatura da UFBA necessita de revisão para se adequar às novas exigências das Diretrizes Curriculares.

Palavras-chave: Licenciatura; Universidade; Formação docente. 


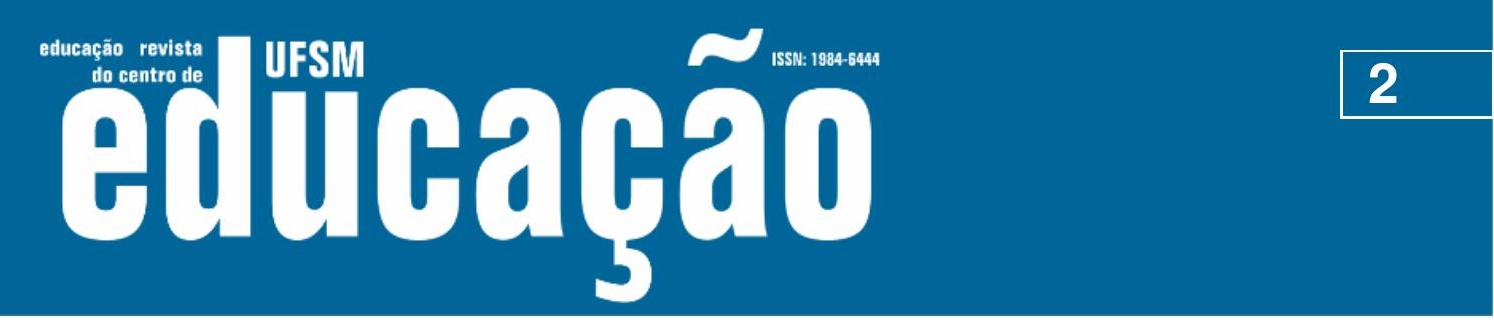

ISSN: 1984-6444 | http://dx.doi.org/10.5902/1984644438110

\section{ABSTRACT}

Teacher training is one of the decisive elements for the improvement of the educational system, since the vision of professionalism underlies a given training program, both in its content and in the way it is organized. Based on this, this study aims to analyze the hours of training activities in UFBA undergraduate courses. Based on an exploratory research of the documentary type, 1,355 mandatory component components were analyzed in the 38 undergraduate curricula of the UFBA, in the daytime and night shift in the period of April / May 2018. The results indicated that in relation to components that include the pedagogical dimensions, supervised internships and pedagogical practices, whose objectives are focused on teacher education, the courses that presented an expressive workload were Pedagogy, followed by Theater, Night shift Computing, Natural Sciences and Physical Education. The course that presented the lowest hourly load in this group was Dance of the day shift. Thus, it is verified that the teacher training in UFBA undergraduate courses needs revision to fit the new requirements of the Curricular Guidelines.

Keywords: Initial Teacher Education; University; Teacher training.

\section{Introdução}

A formação inicial de professores é um campo complexo que envolve um crescente número de atores sociais e, em alguns países, diferentes níveis de ações governamentais. A discussão acerca da formação de professores evoca a relevância desse profissional para a construção do conhecimento, suscitando debates sobre o desempenho do seu papel político-pedagógico-social na sociedade e para o desenvolvimento do trabalho, sobretudo por meio da educação superior.

Nas últimas duas décadas tem sido crescente o número de estudos acerca da formação de professores. Apelos por professores de qualidade, resultados de qualidade e escolas de qualidade se tornaram metas para os políticos, levando a numerosos relatórios sobre o ensino, a formação de professores e a profissão (CUMMING; JASMAN, 2003).

Algumas ações importantes no campo de formação inicial de professores se relacionam à compreensão da organização das atuais configurações curriculares dos cursos de Licenciatura, que podem indicar a realidade do modelo formativo vigente no nosso país. 


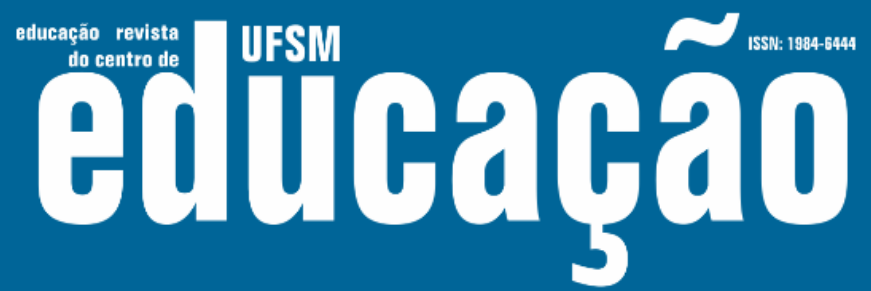

ISSN: 1984-6444 | http://dx.doi.org/10.5902/1984644438110

Um dos componentes que auxiliam na formação do conhecimento pedagógico dos professores são os componentes curriculares de formação docente. Atualmente, os cursos de formação inicial de professores no Brasil devem ser orientados pela Resolução CNE/CP n. 02/2015 que instituiu as Diretrizes Curriculares Nacionais para a Formação Inicial e Continuada em Nível Superior de Profissionais do Magistério para a Educação Básica (BRASIL, 2015b). Essas diretrizes definem princípios, fundamentos, dinâmica formativa e procedimentos a serem observados nas políticas, na gestão e nos programas e cursos de formação. Com a instituição dessas diretrizes em 2015, ficaram revogadas as diretrizes anteriores (Resoluções $n$. 01/2002 e n. 02/2002 do Conselho Nacional de Educação (CNE), estabelecendo o prazo às instituições de ensino superior para adequação curricular dos cursos de licenciatura até julho de 2017 (BRASIL, 2015b). Contudo, esse prazo foi adiado por três vezes e, atualmente, 22 de dezembro de 2019 é a data limite para a adequação dos cursos (BRASIL, 2019).

Nas novas diretrizes, a principal alteração de impacto para os cursos vigentes foi o aumento da carga horária total, com desdobramento nas dimensões pedagógicas. Tais dimensões abarcam todos os conhecimentos e conteúdos específicos que se vinculem à formação pedagógica e seus fundamentos teóricos, por exemplo, conteúdos de Didática, Psicologia da Educação, Legislação Educacional e outros. O tempo de integralização curricular que antes era de 2.800 horas, destas 1.800 horas para os conteúdos curriculares de natureza científicocultural (BRASIL, 2002d), passou a ser de 3.200 horas, destas, 2.200 horas de atividades formativas devem ser estruturadas por dois núcleos: formação geral e formação profissional (BRASIL, 2015b). Entretanto, ficou mantida a quinta parte da carga horária total do curso a ser dedicada às dimensões pedagógicas para todas as licenciaturas, exceto Pedagogia, que deverá ter maior parte do tempo formativo nestas dimensões. Neste cômputo não devem ser inseridas as práticas pedagógicas e os estágios supervisionados, pois para ambos devem ser dedicadas 400 horas cada (BRASIL, 2005a).

Reconhece-se que os conhecimentos pedagógicos necessários para a formação de professores se configuram como essenciais para a formação dos 


\section{Wsy Eutinaţa}

ISSN: 1984-6444 | http://dx.doi.org/10.5902/1984644438110

futuros docentes. De acordo com Gatti (2016), as condições formativas iniciais contribuem fortemente para a construção identitária do professor, que vão conduzir as formas de atuação educativas e didáticas no seu processo de trabalho. $O$ currículo se apresenta como uma dessas condições. Portanto, deve haver destaque nos componentes curriculares na formação dos professores que foquem o fazer docente, o processo educativo e as práticas pedagógicas (CANDAU, 2008).

Nesse sentido, o presente estudo tem como objetivo analisar a carga horária de formação docente dos cursos de licenciatura da Universidade Federal da Bahia, com base nas Resoluções do CNE instituídas em 2002, considerando que os projetos pedagógicos desses estão em fase de adequação para as novas diretrizes e que tiveram suas últimas reestruturações com data anterior a 2017.

\section{Metodologia}

Trata-se de estudo exploratório, com abordagem qualitativa e do tipo documental. A UFBA, atualmente, tem 38 currículos de cursos de graduação na modalidade Licenciatura, considerando a oferta de cursos diurnos e noturnos, nas 17 áreas a seguir: ciências biológicas, ciências naturais, computação, ciências sociais, dança, desenho e plástica, educação física, filosofia, geografia, história, letras, física, matemática, música, pedagogia, química e teatro.

$O$ acesso às matrizes curriculares e as respectivas ementas dos cursos foi obtido por meio do Sistema Acadêmico $(\mathrm{SIAC})^{1}$ da Universidade, que disponibiliza para consulta pública as informações pertinentes para a pesquisa. Deste modo, foi verificada na matriz curricular de cada licenciatura a carga horária ofertada nos componentes curriculares voltados para formação pedagógica (dimensões pedagógicas, estágios e práticas pedagógicas) e para formação técnico-científica no rol de disciplinas obrigatórias. No total, foram analisados 1.355 componentes curriculares obrigatórios, distribuídos nos 38 currículos, no período de abril/maio de 2018. Foram eleitos para esta pesquisa apenas os cursos presenciais, cuja oferta é regular e permanente e por passarem por atualizações e avaliações periódicas. A 


\section{Hsm entolabá}

ISSN: 1984-6444 | http://dx.doi.org/10.5902/1984644438110

análise dos dados foi realizada a partir do cálculo de proporção no Excel do Microsoft Office.

Quanto ao procedimento de análise, consistiu em uma análise documental, cujas operações sistemáticas (codificação de informação e estabelecimentos de categorias) visaram analisar e estudar os vários documentos (ementas curriculares) no intuito de descobrir as circunstâncias com as quais podem estar relacionados (RICHARDSON, 2012). Destarte, essa análise foi estruturada em três etapas: (1) análise preliminar dos documentos e organização do mesmo, envolvendo a leitura exaustiva do material, considerando as cinco dimensões propostas por Cellard (2008): contexto no qual foram produzidos os documentos, os autores, a autenticidade e confiabilidade do texto, a sua natureza, os conceitos-chaves e a lógica interna do texto; (2) a exploração do material, com a administração sistemática dos dados, realizando a organização, com base nas categorias predefinidas; (3) tratamento dos resultados, baseando-se nas decisões resultantes das etapas anteriores, buscando fornecer interpretações coerentes, conjugando abordagens indutivas e dedutivas, tendo como referencial a temática e o problema da pesquisa (CELLARD, 2008).Como resultado, a categoria e as subcategorias preestabelecidas, a partir do referencial normativo e norteador da pesquisa, foram: carga horária (categoria principal) e formação docente, técnico-científicos, dimensões pedagógicas, práticas pedagógicas e estágios supervisionados (subcategorias).

\section{Resultados}

\section{A composição curricular dos cursos de licenciaturas da UFBA}

Para Gatti e colaboradores (2010) as licenciaturas são cursos, que pela legislação, têm como propósito formar profissionais na área da educação seja ela: básica, infantil; fundamental; médio e ou profissional. Mas o que se percebe é a fragilidade da formação deste profissional pelo currículo que as instituições formadoras oferecem. Essa é a grande preocupação que aparece nos debates em organizações tanto mundiais quanto nacionais. 


\section{OFWH

ISSN: 1984-6444 | http://dx.doi.org/10.5902/1984644438110

Esse estudo, especificamente, tratou de analisar a formação docente ofertada nos cursos de licenciatura da UFBA. Além disso, também foi verificado se os cursos estão cumprindo a orientação das Diretrizes Curriculares de oferta de 400 horas de prática e de pelo menos um quinto da carga horária total de tempo dedicado às dimensões pedagógicas, com exceção de pedagogia, que deve ter predominância desse tipo de componentes na formação.

Destaca-se que para investigação da formação acadêmica inicial, a formação docente está relacionada neste estudo à carga horária de componentes curriculares que tratam dos fundamentos epistemológicos, sociológicos, psicológicos, às didáticas e metodologias e práticas de ensino, estágio curricular e trabalho de conclusão de curso, conforme Parecer 197/2004 do CNE (BRASIL, 2005a). A formação técnica se relaciona aos componentes curriculares específicos do conhecimento técnico do curso e que não são voltadas à dimensão pedagógica.

Destaca-se também que esse estudo se baseou apenas na análise dos componentes curriculares obrigatórios dos cursos de licenciatura, perfazendo o currículo mínimo obrigatório a ser integralizado pelos estudantes. Os dados apresentados no quadro e gráficos a seguir foram extraídos das ementas de cada componente curricular que compõe o currículo de cada curso. Nestas ementas estão identificadas as horas-aulas dedicadas às aulas práticas e teóricas, bem como, a descrição da natureza (obrigatória ou optativa), modalidade (disciplina, atividade, estágio, trabalho de conclusão de curso, perfil da ementa e conteúdos. Com base nessas informações, foi possível enquadrar esses dados nas subcategorias de análise supracitadas. 


\section{Nusw entorata}

ISSN: 1984-6444 | http://dx.doi.org/10.5902/1984644438110

Quadro 1 - Carga horária de formação docente e técnico-científica por grupos dos cursos de licenciatura da Universidade Federal da Bahia. Salvador, 2018.

\begin{tabular}{|c|c|c|c|c|c|}
\hline NOME DO CURSO & $\begin{array}{c}\text { TOTAL CH } \\
\text { OBRIGATÓRIAS }\end{array}$ & $\begin{array}{c}\text { CHCC } \\
\text { TECNICAS }\end{array}$ & $\begin{array}{c}\text { CH CC } \\
\text { TECNICAS (\%) }\end{array}$ & \begin{tabular}{|c|} 
CH TOTAL DE \\
FORMAÇÃo \\
DOCENTE
\end{tabular} & $\begin{array}{l}\text { CH TOTAL DE } \\
\text { FORMAÇÃO } \\
\text { DOCENTE (\%) }\end{array}$ \\
\hline Ciências Biológicas - Diurno & 2873 & 2057 & $71,60 \%$ & 816 & $28,40 \%$ \\
\hline Ciências Sociais - Diurno & 2074 & 1496 & $72,13 \%$ & 578 & $27,87 \%$ \\
\hline Dança - Diurno & 2669 & 2091 & $78,34 \%$ & 578 & $21,66 \%$ \\
\hline Educação Física - Diurno & 2720 & 1360 & $50,00 \%$ & 1360 & $50,00 \%$ \\
\hline Filosofia - Diurno & 2312 & 1530 & $66,18 \%$ & 782 & $33,82 \%$ \\
\hline Física - Diurno & 2754 & 1666 & $60,49 \%$ & 1088 & $39,51 \%$ \\
\hline Geografia - Diurno & 2414 & 1700 & $70,42 \%$ & 714 & $29,58 \%$ \\
\hline História - Diurno & 2618 & 1870 & $71,43 \%$ & 748 & $28,57 \%$ \\
\hline Letras: Inglês - Diurno & 2176 & 1666 & $76,56 \%$ & 510 & $23,44 \%$ \\
\hline Letras: Espanhol - Diurno & 2176 & 1666 & $76,56 \%$ & 510 & $23,44 \%$ \\
\hline $\begin{array}{l}\text { Letras: Letras Vernáculas e } \\
\text { Inglês - Diurno }\end{array}$ & 3128 & 2346 & $75,00 \%$ & 782 & $25,00 \%$ \\
\hline $\begin{array}{l}\text { Letras: Letras Vernáculas e } \\
\text { Francês - Diurno }\end{array}$ & 3128 & 2346 & $75,00 \%$ & 782 & $25,00 \%$ \\
\hline $\begin{array}{l}\text { Letras:Letras Vernáculas e } \\
\text { Espanhol - Diurno }\end{array}$ & 3128 & 2346 & $75,00 \%$ & 782 & $25,00 \%$ \\
\hline $\begin{array}{l}\text { Letras: Letras Vernáculas e } \\
\text { Italiano - Diurno }\end{array}$ & 3128 & 2346 & $75,00 \%$ & 782 & $25,00 \%$ \\
\hline $\begin{array}{l}\text { Letras: Letras Vernáculas e } \\
\text { Alemão - Diurno }\end{array}$ & 3128 & 2346 & $75,00 \%$ & 782 & $25,00 \%$ \\
\hline $\begin{array}{l}\text { Letras: Português Como Língua } \\
\text { Estrangeira - Diurno }\end{array}$ & 2482 & 1564 & $63,01 \%$ & 918 & $36,99 \%$ \\
\hline Letras - Português - Diurno & 1938 & 1428 & $73,68 \%$ & 510 & $26,32 \%$ \\
\hline $\begin{array}{l}\text { Licenciatura em Ciências } \\
\text { Naturais - Diurno }\end{array}$ & 2907 & 1411 & $48,54 \%$ & 1496 & $51,46 \%$ \\
\hline $\begin{array}{l}\text { Licenciatura em Desenho e } \\
\text { Plástica - Diurno }\end{array}$ & 2822 & 2040 & $72,29 \%$ & 782 & $27,71 \%$ \\
\hline Licenciatura em Teatro - Diurno & 2278 & 884 & $38,81 \%$ & 1394 & $61,19 \%$ \\
\hline Matemática - Diurno & 2788 & 1700 & $60,98 \%$ & 1088 & $39,02 \%$ \\
\hline Música - Diurno & 2516 & 1462 & $58,11 \%$ & 1054 & $41,89 \%$ \\
\hline Música: Violão - Diurno & 2584 & 1530 & $59,21 \%$ & 1054 & $40,79 \%$ \\
\hline Música: Piano - Diurno & 2516 & 1462 & $58,11 \%$ & 1054 & $41,89 \%$ \\
\hline Pedagogia - Diurno & 2669 & 119 & $4,46 \%$ & 2550 & $95,54 \%$ \\
\hline Química - Diurno & 2975 & 2023 & $68,00 \%$ & 952 & $32,00 \%$ \\
\hline Ciências Biológicas - Noturno & 2873 & 2057 & $71,60 \%$ & 816 & $28,40 \%$ \\
\hline Computação - Noturno & 2499 & 1122 & $44,90 \%$ & 1377 & $55,10 \%$ \\
\hline Dança - Noturno & 2482 & 1632 & $65,75 \%$ & 850 & $34,25 \%$ \\
\hline Física - Noturno & 2754 & 1530 & $55,56 \%$ & 1224 & $44,44 \%$ \\
\hline Geografia - Noturno & 2414 & 1700 & $70,42 \%$ & 714 & $29,58 \%$ \\
\hline História - Noturno & 2618 & 1836 & $70,13 \%$ & 782 & $29,87 \%$ \\
\hline Letras - Noturno & 2006 & 1496 & $74,58 \%$ & 510 & $25,42 \%$ \\
\hline Letras: Inglês - Noturno & 2018 & 1508 & $74,73 \%$ & 510 & $25,27 \%$ \\
\hline Letras: Espanhol - Noturno & 2018 & 1508 & $74,73 \%$ & 510 & $25,27 \%$ \\
\hline Matemática - Noturno & 2720 & 1564 & $57,50 \%$ & 1156 & $42,50 \%$ \\
\hline Pedagogia - Noturno & 2669 & 119 & $4,46 \%$ & 2550 & $95,54 \%$ \\
\hline Química - Noturno & 2958 & 1802 & $60,92 \%$ & 1156 & $39,08 \%$ \\
\hline
\end{tabular}

Fonte: Dados construídos por meio do acesso online ao site e-MEC, SIAC-UFBA. 


\section{TH: Usm

ISSN: 1984-6444 | http://dx.doi.org/10.5902/1984644438110

Legenda do Quadro 1: CH - carga horária; CC - componentes curriculares; Formação docente componentes curriculares obrigatórios que se referem aos fundamentos epistemológicos, sociológicos, psicológicos, às didáticas e metodologias e práticas de ensino, estágio curricular e trabalho de conclusão de curso; Técnicas - componentes curriculares obrigatórios que se referem à formação específica da área do conhecimento.

Verifica-se que os cursos de Letras do turno diurno tendem a ofertar maior carga horária obrigatória, indo além de 3.000 horas. Por outro lado, o curso de Letras do Noturno apresenta menor carga horária de componentes curriculares obrigatórios, cerca de 2.000 horas. Com relação à carga horária dos componentes classificados como técnicos, os cursos de Dança diurno $(78,34 \%)$ e os de Letras em geral (variando entre $73,68 \%$ e $76,56 \%$ ) apresentaram maior proporção. Os que apresentaram menor proporção foram os de Pedagogia diurno e noturno $(4,46 \%)$, Teatro (38,81\%), Computação (44.90\%) e Ciências Naturais (48,54\%).

No Gráfico 1, é possível identificar que na formação docente, que contemplam os fundamentos epistemológicos, sociológicos, psicológicos, às didáticas e metodologias, práticas de ensino, estágios curriculares e trabalhos de conclusão de curso, o curso que apresentou expressiva carga horária foi o de Pedagogia do noturno e diurno $(95,54 \%$ da carga horária total), seguido de Teatro $(61,19 \%)$, Computação $(55,1 \%)$, Ciências Naturais $(51,46 \%)$ e Educação Física $(50 \%)$. Os cursos que apresentaram menor carga horária nesse grupo foram os de Dança, diurno $(21,66 \%)$ e os de Letras (entre 23 e $25 \%$ ), com exceção do curso de Letras como língua estrangeira - Português que apresentou $36,99 \%$ da carga horária obrigatória de formação docente. 


\section{H Hesm

ISSN: 1984-6444 | http://dx.doi.org/10.5902/1984644438110

Gráfico 1 - Carga horária técnico-científica e de formação docente dos componentes curriculares

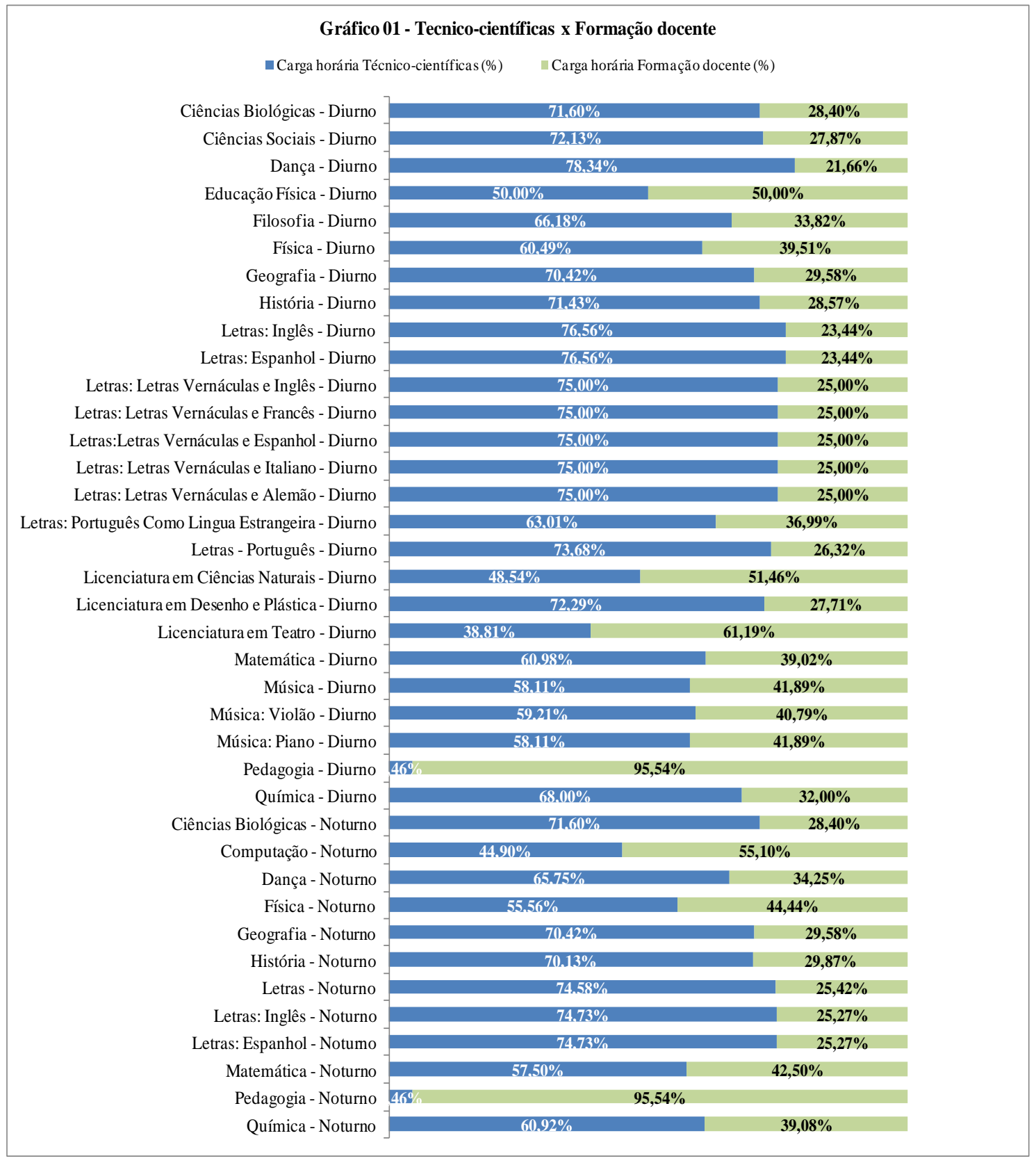

Fonte: elaboração dos autores 


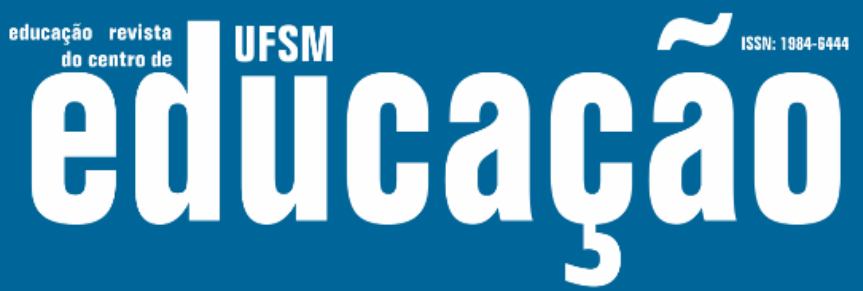

ISSN: 1984-6444 | http://dx.doi.org/10.5902/1984644438110

Com relação às dimensões pedagógicas, as Diretrizes Curriculares orientam a oferta de um quinto da carga horária total para componentes curriculares dedicados a estas dimensões, exceto Pedagogia.

Nesse trabalho, a carga horária das dimensões pedagógicas foi calculada com base na carga horária total de cada curso, como preconiza o CNE (BRASIL, 2002c). Os resultados estão apresentados no Gráfico 02 a seguir. Com a soma das cargas horárias dos componentes curriculares identificados como pedagógicos, excetuando as horas dedicadas às práticas, foi possível constatar se os cursos se enquadram no mínimo a ser cumprido nas referidas dimensões.

Conforme representado no Gráfico 02, verifica-se que apenas o curso de Computação está cumprindo a carga horária mínima para as dimensões pedagógicas. O curso de Pedagogia, que deveria apresentar predominância de carga horária dessa dimensão, atualmente oferta $42,08 \%$ da carga horária total. Seguindo em ordem decrescente, os cursos de Computação (20,92\%), Educação Física $(14,52 \%)$, Teatro $(13,37 \%)$ e Física noturno $(12,65)$ foram os que apresentaram maior concentração da dimensão pedagógica ofertada. $O$ curso que apresenta menor carga horária de dimensão pedagógica foi o de Letras (variando entre 0,93 e 4,66\%), com exceção de Letras como segunda língua - Português $(5,78 \%)$, Ciências Sociais (1,55\%), Ciências Biológicas diurno (2,74\%), Geografia noturno e diurno $(2,75 \%)$, Matemática diurno $(3,73 \%)$ - enquanto o noturno ofertou $(12,25 \%)$. 


\section{Actusn

ISSN: 1984-6444 | http://dx.doi.org/10.5902/1984644438110

Gráfico 02 - Dimensões Pedagógicas

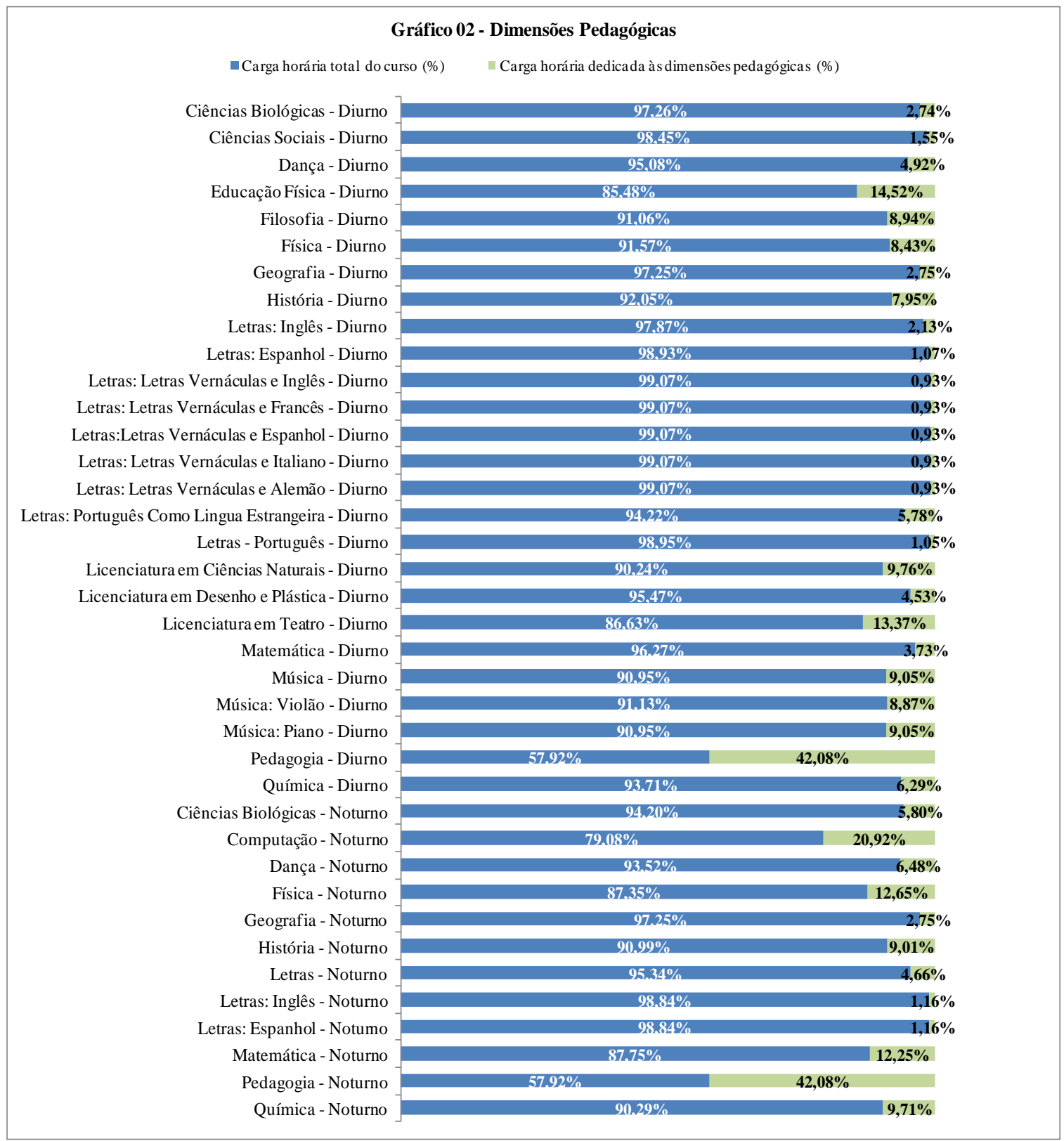

Fonte: elaboração dos autores

A carga horária de estágios e de prática pedagógica também foram analisados nesse estudo. Há a recomendação nas DCN (BRASIL, 2002d) que os cursos de licenciatura ofereçam, no mínimo, 400 horas de estágio curricular e 400 horas de prática pedagógica. 


\section{El|lिa

ISSN: 1984-6444 | http://dx.doi.org/10.5902/1984644438110

De acordo com os dados apresentados, dos 38 cursos analisados, os que estão cumprindo as recomendações das DCN em ofertar, no mínimo, 400 horas de estágio curricular são 24: Ciências Biológicas (noturno e diurno), Educação Física, Física (diurno e noturno), Geografia (noturno e diurno), os de Letras Vernáculas (inglês, francês, espanhol, italiano e português como língua estrangeira), Ciências Naturais, Desenho e Plástica, Teatro, Matemática (diurno e noturno), Música (incluindo com violão e piano), Computação, Dança (noturno) e Química (noturno).

Os 14 que não estão cumprindo são: Pedagogia (noturno e diurno), Ciências Sociais, Dança (diurno), Filosofia, História (diurno e noturno), Letras Inglês (noturno e diurno), Letras Espanhol (noturno e diurno), Letras Português (noturno e diurno) e Química (diurno). Os cursos e suas respectivas horas de estágio estão demonstrados no gráfico 3 abaixo:

Gráfico 03 - Carga horária de Estágios Supervisionados

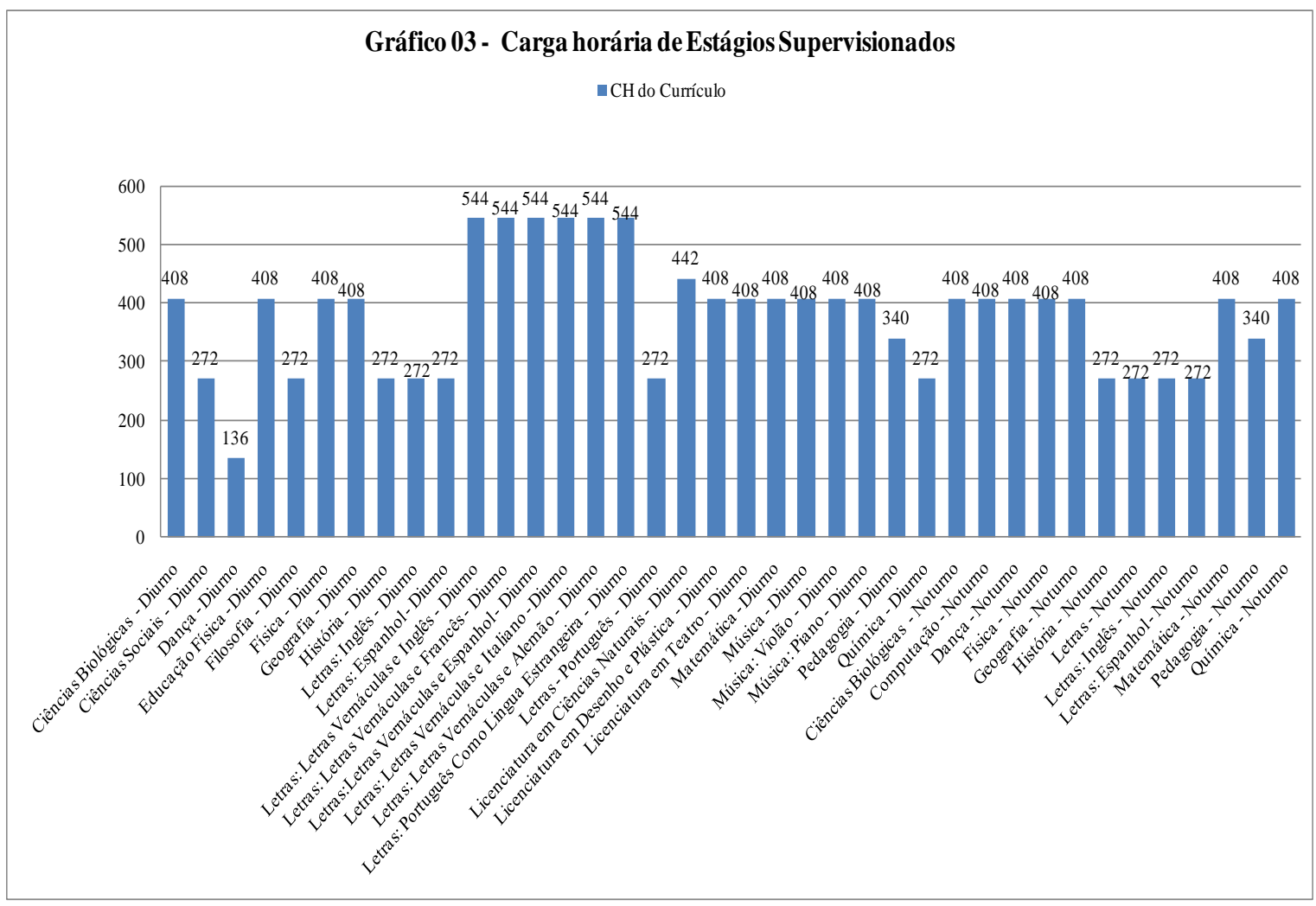

Fonte: elaboração dos autores 


\section{Nusm

ISSN: 1984-6444 | http://dx.doi.org/10.5902/1984644438110

Com relação às práticas pedagógicas, nos currículos não há componente específico dedicados a elas, em conformidade com o entendimento já expresso pelo CNE, no Parecer 28/2001 que diz: "a prática na matriz curricular dos cursos de formação não pode ficar reduzida a um espaço isolado" (BRASIL, 2002a). Elas estão distribuídas em componentes curriculares de conteúdo pedagógico cuja carga horária é teórica e prática. Assim, desses componentes somou-se as cargas horárias referentes às práticas pedagógicas, excluindo-se nesse cômputo o que se refere àscargas horáriasindicadascomoteóricas. Com o resultado, demonstrado no gráfico 4, é possível constatar que apenas 10 dos 38 cursos estão ofertando 400 horas: Educação Física, Física (diurno e noturno), Ciências naturais, Teatro, Matemática (diurno), Pedagogia (noturno e diurno) e Química (diurno e noturno). Dentre esses, os que tiveram maior carga horária de práticas pedagógicas foram os de Pedagogia noturno e diurno $(30,57 \%)$, Teatro $(26,12 \%)$, Ciências Naturais $(25,15 \%)$ e Matemática diurno $(20,12 \%)$.

Gráfico 04 - Carga horária de Práticas Pedagógicas

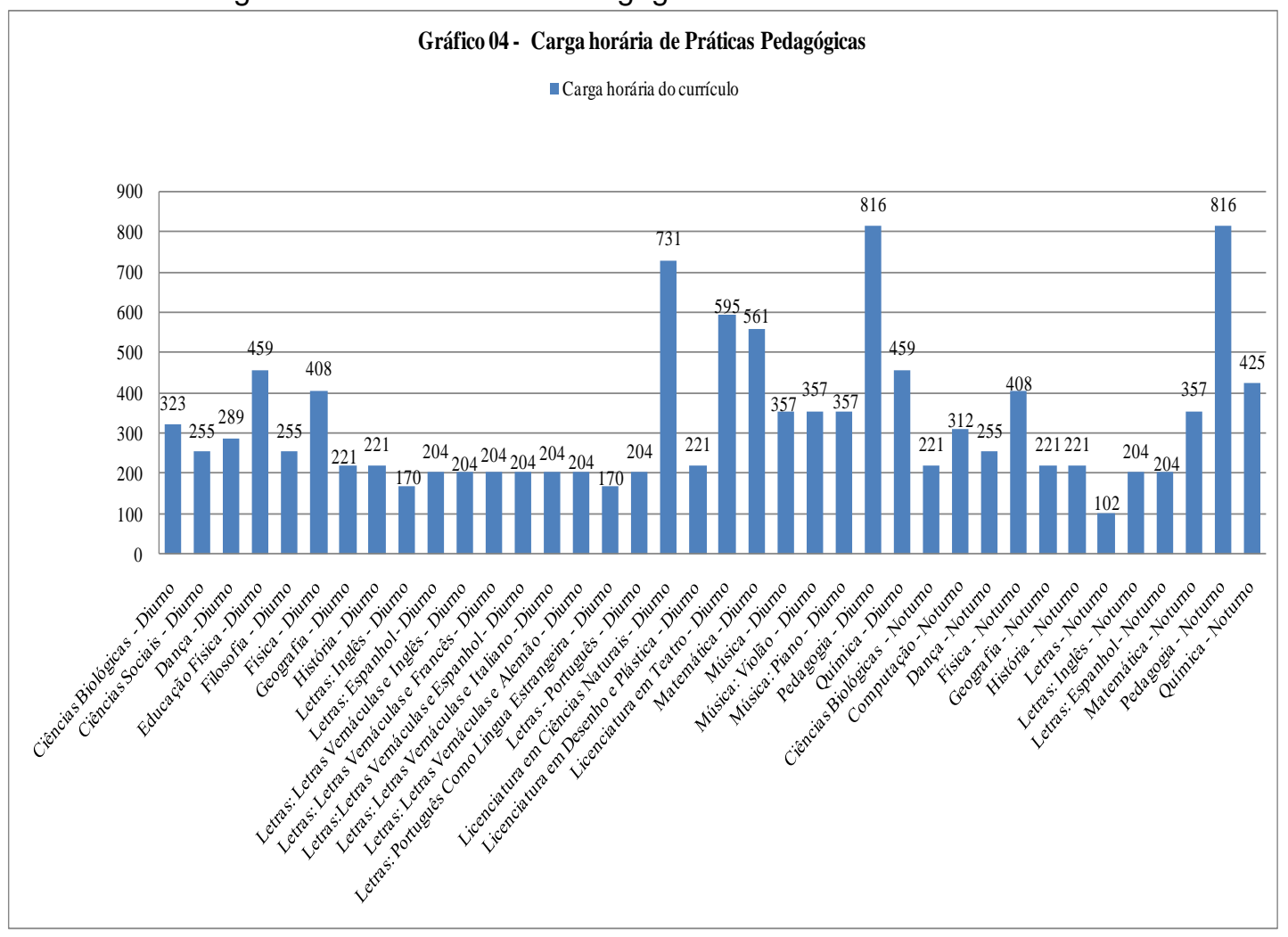

Fonte: elaboração dos autores 


\section{Hsm eltibará}

ISSN: 1984-6444 | http://dx.doi.org/10.5902/1984644438110

\section{Discussão}

Reconhece-se que a formação docente transcende a especificidade de uma área disciplinar do conhecimento. Para Shulman (2005), ela abrange o conjunto dos conhecimentos próprios de qualquer profissional do ensino e garantem a especificidade da profissão docente. Estão incluídos nesse conjunto os conhecimentos relativos ao currículo, aos contextos educacionais, aos propósitos e aos valores educacionais, aos alunos e às suas características e, sobretudo, às teorias e princípios próprios dos processos de ensinar e aprender.

É com base na constatação da importância desse conjunto de conhecimentos que esse estudo se propôs a analisar a carga horária destinada à formação docente. Para tanto, foi necessário isolar e analisar a carga horária de estágios curriculares, de práticas pedagógicas, de dimensão pedagógica, de técnico-científicas e a soma dos componentes que correspondem à formação docente.

Nosso estudo apontou que os cursos de Dança e os de Letras em geral apresentaram maior carga horária na formação técnico-científica. Estes também apresentaram pouca concentração de carga horária voltada para formação docente, o que já era de se esperar, já que ficou demonstrada a ênfase na formação técnica dessas licenciaturas. Por outro lado, os cursos de Pedagogia, Teatro, Computação, Ciências Naturais e Educação Física ofertam mais componentes curriculares de formação docente quando comparados aos demais.

Esses resultados corroboram com os do estudo de Gatti e colaboradores (2010) em que demonstrou que os cursos de licenciatura em Letras representaram $51,4 \%$ da sua carga horária em disciplinas relativas aos conhecimentos disciplinares da área. Apenas $11 \%$ da carga horária total desses cursos foram dedicadas à formação para docência.

Para Libâneo (2009), o curso de licenciatura em pedagogia tende a concentrar maior parte de sua carga horária voltada para a formação docente, enquanto os outros cursos de licenciatura em formações específicas possuem uma grande concentração de conteúdos nas respectivas áreas de conhecimento, em detrimento da formação docente. Para Barretto (2010), essa configuração 


\section{OFWH Eutinaba}

ISSN: 1984-6444 | http://dx.doi.org/10.5902/1984644438110

representa a diferenciação instituída entre o trabalho da professora primária (polivalente) e do professor secundário (especialista em uma disciplina) que permanece até hoje. Essa diferenciação pode ser constatada tanto na estrutura curricular dos cursos de licenciatura - dando ênfase na formação técnica - como nas carreiras, salários, e representações da sociedade, da academia e dos formuladores das políticas.

Para Gatti e colaboradores (2010), mesmo com ajustes parciais em razão das novas diretrizes, verifica-se nas licenciaturas dos professores especialistas a prevalência da histórica ideia de oferecimento de formação com foco na área disciplinar específica, com pequeno espaço para a formação pedagógica (GATTI, 2009). É com base nisso que esta autora defende que adentramos no século XXI com as mesmas condições e orientação do início do século passado.

De forma geral, Gatti (2009) critica a falta de relação entre as disciplinas de formação específicas com as de formação pedagógica nos cursos analisados. É sabido que a formação que contemple apenas elementos técnicos e específicos da área reflete uma inconsistência da formação em licenciatura, que pressupõe um domínio da prática (PEREIRA, 1999; GATTI Et Al., 2012). Espera-se, portanto, que ocorra a articulação e interdisciplinaridade nesses dois grupos.

Além disso, soma-se este dado à constatação de Dias (2015) que destaca que mesmo que o curso ofereça disciplinas pedagógicas (como Fundamentos da Educação, Didática e Práticas de Ensino), o empenho dos estudantes em disciplinas de conteúdo específico do curso ocorre mais efetivamente, como foi observado no caso da licenciatura em Matemática. Igualmente, estudos com universitários (SOUZA; ESTEVES; SILVA, 2014) vêm demonstrando que mesmo no curso de Pedagogia, os estudantes privilegiam seus estudos em disciplinas específicas de componentes pedagógicos, colocando em segundo plano as voltadas para formação docente. Este fato destoa do objetivo da licenciatura que é formar o educador. Sendo assim, a revisão do processo formativo inicial dos professores deve compor uma agenda política urgente a fim de mudanças em prol de um dispositivo social que possibilite transformações na área da educação. Essa discussão tem sido consolidada por alguns teóricos (NÓVOA, 2001; SCHÖN, 1992; ZEICHNER, 1993), 


\section{OF LSH Eutuab̧a}

ISSN: 1984-6444 | http://dx.doi.org/10.5902/1984644438110

que compreendem os espaços de reflexão como necessários para formação crítica dos professores.

Essa autora também aponta que mesmo as disciplinas que se enquadram como formação docente, se caracterizam predominantemente como teóricas e não práticas, quando deveria haver um equilíbrio entre esses dois eixos. No nosso estudo, apenas os cursos de Educação Física, Ciências Naturais, Teatro e Física (noturno) conseguiram obter um equilíbrio idealizado entre a carga horária de formação técnica e de formação docente.

Para Kuenzer (2011), foram feitos esforços para reestruturar as licenciaturas ao status de curso com identidade, em substituição ao caráter de complementaridade do bacharelado. Até a publicação da Lei de Diretrizes e Bases em 1996, a regulamentação do preparo de docentes para escola secundária se caracterizava pela fórmula $3+1$, em que as disciplinas de natureza pedagógica, cuja duração prevista era de um ano, justapunham-se às disciplinas de conteúdo, com duração de três anos. No entanto, o que se verifica é que o modelo anterior não foi completamente superado, ainda há predominância da formação técnica em detrimento da formação docente.

Segundo as Diretrizes Curriculares Nacionais para a Formação dos Professores da Educação Básica, em nível superior, os componentes relacionados à docência devem ser prioridades na base da formação para que os futuros profissionais possam, a partir das habilidades aprendidas, articularem a teoria e prática no exercício da profissão, contribuindo para uma revalorização do ensino básico (BRASIL, 2015b).

Está expresso no parágrafo $5^{\circ}$ do Art. 13 que

Nas Licenciaturas, curso de Pedagogia, em educação infantil e anos iniciais do ensino fundamental a serem desenvolvidas em projetos de cursos articulados, deverão preponderar os tempos dedicados à constituição de conhecimento sobre os objetos de ensino, e nas demais licenciaturas o tempo dedicado às dimensões pedagógicas não será inferior à quinta parte da carga horária total. (Brasil, 2015b, p. 11-12) 


\section{FsM Eutinaţa}

ISSN: 1984-6444 | http://dx.doi.org/10.5902/1984644438110

Os resultados desse estudo refletem, portanto, a pouca atenção que vem sendo dispensada às dimensões pedagógicas nos cursos de licenciatura. Nenhum curso está cumprindo com o esperado um quinto da carga horária do curso. O que mais se aproximou do um quinto foi o curso de Computação, que também apresentou boa concentração de carga horária de formação docente e o mínimo exigido para estágio curricular. No entanto, esse curso não apresentou as 400 horas de prática pedagógica.

As DNC orientam que sejam ofertadas 400 horas de prática pedagógica ao longo da formação acadêmica nos cursos de licenciatura. Apenas os cursos de Educação Física, Pedagogia (noturno e diurno), Física, Ciências Naturais, Teatro, Matemática (diurno), Química (diurno e noturno) e Física (noturno) vêm ofertando o mínimo da carga horária recomendada.

As práticas pedagógicas devem perfazer todo o percurso formativo, desde 0 início do curso (BRASIL, 2015a). São intrínsecas ao âmbito do ensino e devem estar articuladas com a teoria (BRASIL, 2002a). São práticas formadoras, que preparam o educando para ser docente e para lidar com os desafios de ser educador, enquanto for concebida na criticidade, sem que se dissocie da sua relação com a teoria, posto que, prática sem teoria é ativismo e teoria sem prática é discurso vazio (FREIRE, 2002). É na aprendizagem prática que se aprende a agir como um profissional (SHULMAN, 2005). Logo, o não atendimento à carga horária de práticas podem refletir no perfil do egresso dessas licenciaturas não condizentes com o ideal de formação do professor.

Nessa perspectiva, o CNE ao determinar um quantitativo de carga horária específica para as práticas, sem que haja a necessidade de isolá-las em um componente, evidencia a importância da prática e da sua relação com a teoria no cotidiano pedagógico. Também destaca que apesar de teoria e prática estarem interrelacionadas, estas possuem características e finalidades próprias, entre elas a importância na formação da identidade do professor como educador (BRASIL, 2002a). O CNE também orienta que elas podem ser concebidas como "núcleo ou como parte de disciplinas ou de outras atividades formativas" (BRASIL, 2005b, p.3). 


\title{
Tusm Eutuab̧a
}

ISSN: 1984-6444 | http://dx.doi.org/10.5902/1984644438110

Isto não inclui aquelas relacionadas aos fundamentos técnico-científicos correspondentes a uma determinada área do conhecimento, pois,

\begin{abstract}
As disciplinas relacionadas com a educação que incluem atividades de caráter prático podem ser computadas na carga horária classificada como prática como componente curricular, mas o mesmo não ocorre com as disciplinas relacionadas aos conhecimentos técnico-científicos próprios da área do conhecimento para a qual se faz a formação. Por exemplo, disciplinas de caráter prático em Química, cujo objetivo seja prover a formação básica em Química, não devem ser computadas como prática como componente curricular nos cursos de licenciatura. Para este fim, poderão ser criadas novas disciplinas ou adaptadas as já existentes, na medida das necessidades de cada instituição (BRASIL, 2005b, p.3).
\end{abstract}

Portanto, os atores envolvidos no processo de construção do projeto pedagógico não devem supervalorizar os conhecimentos teóricos desprezando as práticas, tampouco relegá-las apenas aos estágios supervisionados (BRASIL, 2002a).

Do mesmo modo, não se confundem as práticas pedagógicas com as de estágio supervisionado (BRASIL, 2015a).

Para Dias e Souza (2017) um momento crucial para formação de professores, que podem impulsionar mudanças em relação à profissão, é a vivência em estágio curricular. O momento do estágio propicia uma manifestação de relações novas entre os conteúdos já cursados nas disciplinas de formação e a realidade escolar. $A$ recomendação das $\mathrm{DCN}$ é de que carga horária de estágio curricular seja, no mínimo, 400 horas. Nosso estudo revelou que apenas 24 dos 38 cursos analisados estão cumprindo essa recomendação. O que chamou mais atenção é que o curso de Pedagogia, apesar de ter maior concentração de componentes curriculares de formação docente e de ofertar 816 horas de prática pedagógica, não oferta as 400 horas de estágio.

Um estudo desenvolvido por Flores (2015) demonstrou que o estágio foi visto pelos estudantes dos cursos de licenciatura analisados como um componente-chave do seu processo de aprender a ensinar, uma vez que lhes possibilita o contato com escolas e alunos reais. Esse estudo de Flores (2015) também apontou que os estudantes consideraram o conteúdo do currículo como aspectos mais marcantes na formação inicial. 


\section{Hsm entioará}

ISSN: 1984-6444 | http://dx.doi.org/10.5902/1984644438110

Alguns programas foram criados para melhor qualificar a formação inicial de professores para a educação básica. O PIBID (BRASIL, 2010), por exemplo, foi criado pelo decreto 7.219 em 24 de junho de 2010 e expõe claramente que sua finalidade é fomentar a iniciação à docência e melhor qualificá-la, visando à melhoria do desempenho da educação básica. Para Gatti (2014) programas desse tipo são sinalizadores de que as licenciaturas não estão oferecendo formação adequada aos futuros docentes.

Para Nóvoa (2011), apenas ter leis que determinem a formação mínima para formação não é suficiente, são necessárias mudanças que possibilitem a esses estudantes uma formação mais sólida e que no futuro tragam resultados satisfatórios para a sociedade; pois esse profissional atua na transformação social de toda uma sociedade, por isso é importante trazer para a formação deste profissional um novo espaço de reconstrução, para reforçar, colaborar e cooperar na formação destes futuros professores. É seguindo esse pensamento que Gatti e colaboradores (2010) também trazem a mesma preocupação quando, em seus estudos, os autores entendem que formar bons professores, não pode ser pensado apenas nas ciências e nos seus diversos campos, mas na função social que este profissional é responsável, ou seja, transmitir conhecimentos a novas gerações, transformar seres humanos em seres pensantes, consolidar neles conhecimentos adquiridos por anos e garantir praticas coerentes com a vida civil.

No parágrafo 2 do Art. $2^{\circ}$ das Diretrizes Curriculares está descrito que 0 exercício da docência está definido como a ação do profissional do magistério permeada por dimensões técnicas, políticas, éticas e estéticas por meio de sólida formação, envolvendo o domínio e manejo de conteúdos e metodologias, diversas linguagens, tecnologias e inovações, contribuindo para ampliar a visão e a atuação desse profissional (BRASIL, 2015b).

Para Tardif (2000) são os saberes pessoais, de formação profissional (provenientes de sua formação escolar e acadêmica), saberes disciplinares, saberes curriculares e os da experiência que se constituem o saber docente. Os de formação profissional compreendem esse tipo de análise desenvolvida nessa pesquisa. Embora a formação de professores não seja o único caminho para se conseguir 


\section{Hsm edtoará}

ISSN: 1984-6444 | http://dx.doi.org/10.5902/1984644438110

mudanças no sistema educacional, destaca-se que ela constitui um dos elementos decisivos para melhorar a qualidade do ensino e da aprendizagem nas escolas.

\section{Considerações Finais}

A análise central desse estudo abarcou a quantidade de carga horária dos componentes curriculares da formação docente dos cursos de licenciatura do turno diurno e noturno da Universidade Federal da Bahia, a partir dos currículos dos 38 cursos.

Mediante parâmetros estabelecidos pelas diretrizes que norteiam a construção dos projetos pedagógicos de curso e, por consequência, define critérios específicos para se estabelecer a qualidade na formação do futuro professor, constatou-se que os currículos da UFBA não atendem ao mínimo de carga horária que deveria ser dedicada a essa formação. Dos 38 currículos somente 26,3\% atingem o mínimo exigido de horas para as práticas pedagógicas, 63,1\% ofertam o mínimo de horas exigidas para os estágios supervisionados; somente 3,8\%, que equivale a 01 curso está em conformidade com o quantitativo definido para as dimensões pedagógicas. No que concerne, a carga horária total de dedicação à formação docente, apenas 5 cursos ofertam mais de $50 \%$ da carga horária em componentes curriculares obrigatórios nesta dimensão. Fatores que indicam uma concepção de cursos predominantemente teórico-científicos em detrimento da formação da pedagógica.

No entanto, a baixa carga horária para a formação docente pode ser preocupante em se tratando de processo formativo de futuros professores.

Mesmo com os avanços obtidos desde a publicação da Lei n. 9.394/96, Lei de Diretrizes e Bases da Educação Nacional, a questão da formação dos professores tem sido um grande desafio para as políticas governamentais e para as instituições de ensino superior que os formam. A estrutura curricular encontrada nesse estudo dos cursos de licenciatura da UFBA evidencia a falta de inovações e avanços em relação à atualização curricular. É necessário repensar acerca das cargas horárias que priorize a formação docente, que habilitem o licenciando a desempenhar uma 


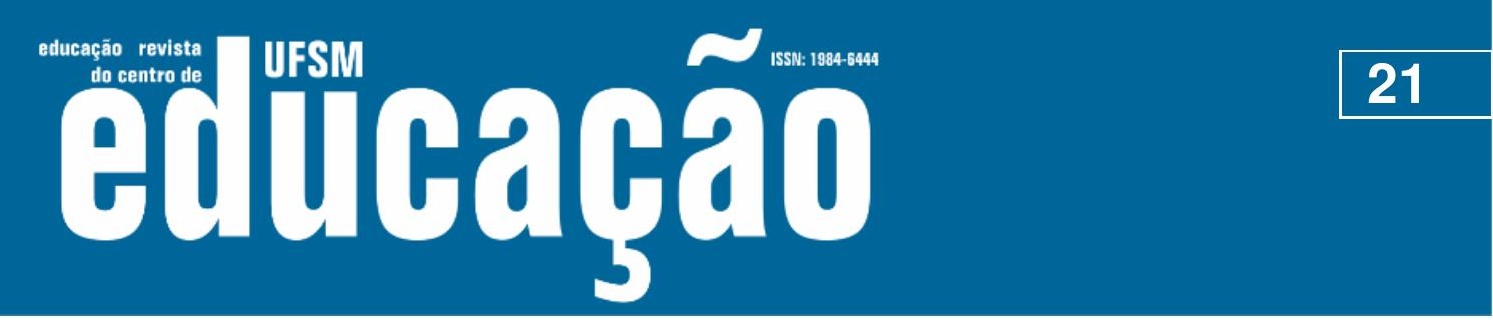

ISSN: 1984-6444 | http://dx.doi.org/10.5902/1984644438110

carreira docente com uma base consistente das práticas cotidianas necessárias ao espaço escolar.

Destaca-se, outrossim, que o caráter documental desse estudo se apresenta como fator limitante. A formação de professores não se restringe ao currículo, uma vez que esta envolve vários espaços dentro e fora da academia que conformam as competências desses profissionais. Assim, à medida que a compreensão acerca da formação identitária do professor vai além do currículo, destaca-se que as biografias dos estudantes que expressam o conhecimento sobre estrutura escolar, sobre currículo e sobre o que é ser professor devem ser levadas em consideração. Certamente, as falas dos estudantes dos cursos de licenciatura acerca da formação docente ofertada poderão revelar com maiores detalhamentos as lacunas no processo formativo de professor.

\section{Referências}

BARRETO, Elba Siqueira de Sá. Trabalho docente e modelos de formação: velhos e novos embates e representações. Cadernos de Pesquisa, v. 20, n. 140, p. 427-443, 2010.

BRASIL. Ministério da Educação. Conselho Nacional de Educação. Parecer CNE/CES 28/2001, de 02 de outubro de 2001. Diário Oficial da União, Brasília, DF, 18 jan. 2002a. Disponível em: http://portal.mec.gov.br/cne/arquivos/pdf/028.pdf. Acesso em: 13 nov. 2017

BRASIL. Ministério da Educação. Conselho Nacional de Educação. Resolução CNE/CP 09/2001, de 8 de maio de 2001. Diretrizes Curriculares Nacionais para a Formação de Professores da Educação Básica, em nível superior, curso de licenciatura, de graduação plena. Diário Oficial da União, Brasília, DF, 18 de jan. 2002b. Seção $\quad 1.010$ p. $31 . \quad$ Disponível em:http://portal.mec.gov.br/cne/arquivos/pdf/rcp01_02.pdf. Acesso em: 02 nov. 2017.

BRASIL. Ministério da Educação. Conselho Nacional de Educação. Resolução CNE/CP 01/2002, de 18 de fevereiro de 2002. Diretrizes Curriculares Nacionais para a Formação de Professores da Educação Básica, em nível superior, curso de licenciatura, de graduação plena. Diário Oficial da União, Brasília, DF, 4 mar. 2002c. Seção 1, p. 8. Disponível em:http://portal.mec.gov.br/cne/arquivos/pdf/rcp01_02.pdf. Acesso em: 13 nov. 2017 


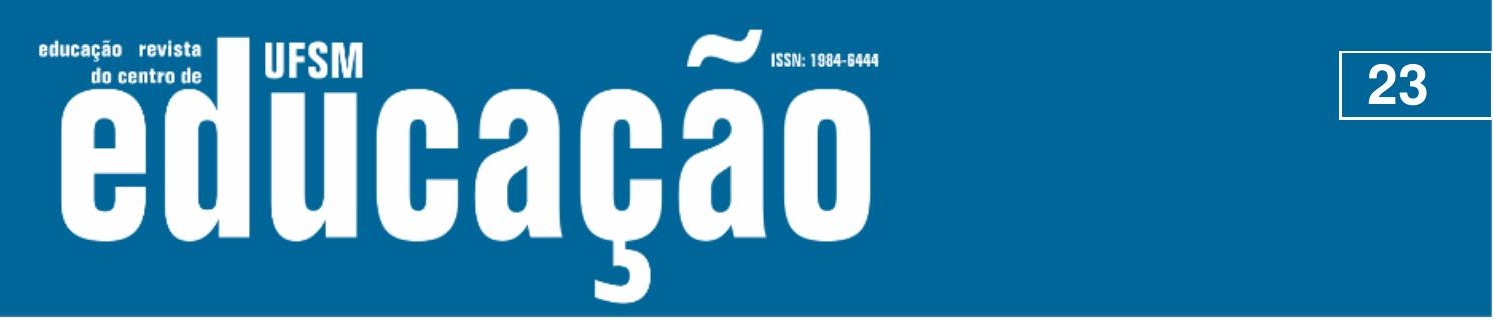

ISSN: 1984-6444 | http://dx.doi.org/10.5902/1984644438110

CELLARD, André. Análise documental. In: POUPART, Jean. et al. A pesquisa qualitativa: enfoques epistemológicos e metodológicos.Tradução de Ana Cristina Nasser. Petropólis: Vozes, 2008. 295-316 p.

CUMMING, J.; JASMAN, AM. Professional teaching standards and quality education. UNESCO: Teacher Status and Qualifications for Education Quality Project, 2003.

DIAS, Marisa da Silva. Atividade do licenciando em matemática: a escolha do curso e o estágio curricular supervisionado. In: Farias, I. M. S. de. et al. (Org.). Didática e a prática de ensino na relação com a formação de professores. Fortaleza: EDUECE, 2015. p. 1836-1847. v. 2. Disponível em: http://www.uece.br/endipe2014/ index.php/2015-02-26-14-08-55. Acesso em: 24 mai. 2017.

DIAS, Marisa da Silva; SOUZA, Neusa Maria Marques de. Contribuições para compreender a formação na licenciatura e na docência. Educação em Revista, n. 33, 2017.

FLORES, Maria Assunção. Formação docente e identidade profissional: tensões e (des)continuidades. Educação, v. 38, n.1, p. 138-146, 2015.

FREIRE, Paulo. Pedagogia da autonomia. 25. ed. São Paulo: Editora Paz e Terra, 2002. (Coleção leitura)

GATTI, Bernardete Angelina. Formação de professores para o ensino fundamental: estudo de currículos das licenciaturas em pedagogia, língua portuguesa, matemática e ciências biológicas. São Paulo: FCC/DPE, 2009.

GATTI, Bernardete Angelina et al., Formação de professores para o ensino fundamental: instituições formadoras e seus currículos. Estudos \& Pesquisas Educacionais, n. 1, p. 95-138, 2010.

GATTI, Bernardete Angelina et al.Análises pedagógico-curriculares para os cursos de licenciatura vinculados às áreas de artes, biologia, história, língua portuguesa, matemática e pedagogia no âmbito da UAB e Parfor. Brasília: Unesco, MEC, Capes, 2012 (Documento Técnico)

GATTI, Bernardete Angelina. Formação de professores: condições e problemas atuais. Revista Internacional de Formação de Professores, 2016, 1 (2): 161-171.

GATTI, Bernardete Angelina. A formação inicial de professores para a educação básica: as licenciaturas. São Paulo: Revista USP. 100, 43-46. Disponível em: https://www.revistas.usp.br/revusp/article/download/76164/79909.

KUENZER, AcaciaZeneida. A formação de professores para o ensino médio: velhos problemas, novos desafios. Educação \& Sociedade, v. 32, n. 116, pp. 667-688, 2011. 


\section{DFEM

ISSN: 1984-6444 | http://dx.doi.org/10.5902/1984644438110

\section{(C) $(1) \otimes$}

This work is licensed under a Creative Commons Attribution-NonCommercial 4.0 International (CC BY-NC 4.0)

\section{Nota}

${ }^{1}$ Disponível em: https://alunoweb.ufba.br/SiacWWW/ListaCursosEmentaPublico.do?cdGrauCurso=01. 